DOI: 10.22616/REEP.2020.029

\title{
An Exploratory Survey on Internationalization at Secondary Schools: International Mobility from the Perspective of Students
}

\author{
Eva Lebduskova ${ }^{1}$ Ing.; Karel Nemejc ${ }^{2}$ Ing., PhD; Jirina Snehotova ${ }^{3}$ Mg. \\ Katerina Tomsikova ${ }^{4}$ Ing.; Emil Kriz ${ }^{5}$ Ing., $\mathrm{PhD}$ \\ Czech University of Life Sciences Prague, Faculty of Agrobiology, Food and Natural Resources ${ }^{1}$ \\ Czech University of Life Sciences Prague, Institute of Education and Communication ${ }^{2,3,4,5}$ \\ Czech Republic \\ lebduskova@af.czu.cz'; nemejc@ivp.czu.cz²; snehotova@ivp.czu.cz ${ }^{3}$ \\ tomsikova@ivp.czu.cz ${ }^{4}$; kriz@ivp.czu.cz ${ }^{5}$
}

\begin{abstract}
Internationalization has become a common phenomenon in educational institutions, and secondary level of education is no exception. In this context, the paper looks into the possibilities of outgoing international mobility in secondary educational institutions. The aim of the study is to map the possibilities of outgoing international mobility in educational institutions and using an exploratory survey to study the perception of international mobility by secondary school students. The target group were 288 students of secondary schools with various specializations. The data collection was carried out on social media and by actively contacting secondary schools across the Czech Republic. The survey was conducted using an anonymous online questionnaire in the period from December 2018 to January 2019. The data were analysed and processed using descriptive statistics. Based on the results, it can be recommended to secondary schools that they should raise students' awareness of outgoing international mobility, organize so-called international days or weeks, transfer experience from students who have participated in international mobility, expand the offer of international mobility, focus more on the specialization aspect of outgoing international mobility, etc. Correlation matrices showed that outgoing international mobility meets students' expectations in the five monitored aspects and benefits their studies.
\end{abstract}

Keywords: Internationalization, international mobility, secondary education, practice abroad.

\section{Introduction}

Internationalization is becoming an integral part of all spheres of life in modern society, including education (Raitskaya, Tikhonova, 2019; Roskosa, Stukalina, 2019). As evidenced by the results of a related research that focused, among other things, on employability of graduates of vocational education (Smekalova, Nemejc, 2016), perceptions of students and academic staff mobility (Petzhold, Bucher, 2018), quality assurance in education (Roskosa, Stukalina, 2018), or professional preparation of teachers (Zhanguzhinova et al., 2018), the process of internationalization is accelerating.

One of the possibilities how to support this area of education is international mobility of students and teachers. Outgoing international mobility can last one or more days, with one-day trips usually organized in the vicinity of the school. Multi-day stays are devised as excursions to one country, one region, or to several countries (Dvorakova, 2012). A lot of students' mobilities can be organized in the framework of EU programmes. ERASMUS + is a mobility programme providing its participants with experience in their fields of study and work by presenting global trends. It promotes the academic, professional and individual development of the participants while contributing to the extension of the worldwide work market (Mizikaci, Arslan, 2019). Participants are then issued a Youthpass certificate as a confirmation of participation in the project, which can also be a welcome addition to the participant's CV. The certificate contains information about the implemented project (date and place, objectives, main activities) as well as a description of the achieved or improved key competences of the participant (Welcome to Youthpass, 2019).

The platform eTwinning, a community for schools in Europe, has been established to promote mobility. Using information and communication technology, the platform enables schools to communicate and cooperate at international level, or at the level of European countries. The portal is available in 28 languages. Established in 2005, eTwinning is currently part of ERASMUS+ and is run by the eTwinning Central Support Service. In the Czech Republic, it is part of the Centre for International Cooperation in 
Education, managed by the National eTwinning Support Service. In this way, eTwinning develops students, their key competences, understanding of cultural differences, while also developing their language skills. As regards teachers, it helps them in their professional development, using different teaching methods (eTwinning is the Community..., 2019, European Commission, 2019).

Another possibility how to help students acquire experience with travelling or studying abroad is to contact an agency that specializes in this kind of study stays. Some agencies also offer the possibility to work as an au pair as well as language courses and various forms of short-term jobs abroad. These agencies include, among others: Student Agency; Czech-us; Studyline; Bohemia institut; Coolagent.

The aim of the study is to map the existing possibilities of outgoing international mobility in secondary educational institutions and to understand how the offered international mobility is perceived by students at selected secondary schools in the Czech Republic.

\section{Methodology}

An exploratory survey was used to map the existing possibilities of international mobility in secondary educational institutions and to understand the perception of international mobility by students. The target group are students of secondary schools of various specializations. The data collection was carried out on social media and by actively contacting secondary schools across the Czech Republic. The survey was conducted using an anonymous online questionnaire in the period from December 2018 to January 2019.

The questionnaire consisted of 24 items, which were formulated as dichotomous (yes - no), trichotomous (yes - no - don't know), multiple choice questions with one correct answer and multiplechoice questions with more than one correct answer with additional comments. One item concerning additional information about and recommendations for outgoing international mobility was an open one. The items in the questionnaire queried the following information:

- respondent identification (gender, age, size of municipality) and the secondary school where they study (region and type of secondary school - grammar school, secondary technical / vocational school, conservatory) (5 items);

- study of foreign languages (1 item);

- students' awareness of outgoing international mobility implemented at their secondary school (2 items);

- participation of students in outgoing international mobility organized by their secondary school (4 items);

- students' expectations before mobility and the fulfilment of their expectations (2 items always with 5 claims);

- overall assessment of outgoing international mobility (10 items).

\section{Results and Discussion}

The data were analysed and processed using descriptive statistics. Summarization of the selected empirical data enabled an insight into the investigated issue and a subsequent interpretation of the findings.

A total of 288 respondents completed the questionnaire, of which $201(69.8 \%)$ were females and $87(30.2 \%)$ were males. The target group for the questionnaire survey were secondary school students; students from all regions of the Czech Republic participated in the survey. The most frequent group were students aged 17-18; a total of $129(44.8 \%)$ students. The second most frequent group were students aged 15-16; a total of $79(27.4 \%)$ students. The group of students aged 19-20 consisted of 66 (22.9\%) students, while only 14 (4.9\%) students were over 20.

The sample consisted of secondary school students from 13 regions of the Czech Republic (the Ústecký Region was not included). The regions with the biggest share of participating students were in descending order: the Pardubice Region (111, i.e. $38.5 \%$ ), the South Moravian Region (81, i.e. $28.1 \%$ ), the Plzen Region (28, i.e. $9.7 \%)$, and Prague (24, i.e. $8.3 \%)$. The sample consisted of $215(74.7 \%)$ students of secondary schools, $58(20.1 \%)$ students of grammar schools, $14(4.9 \%)$ students of secondary vocational schools, and one student of conservatory $(0.3 \%)$. 
A total of $283(98.3 \%)$ respondents study English. It can be expected that English is the primary foreign language for the majority of students. The second most widely studied language and the dominant "second" foreign language is German, studied by 146 students, i.e. $50.7 \%$ of all respondents. The third most widely studied language is Russian with $41(14.2 \%)$ respondents, followed by French with $20(6.9 \%)$ respondents and Spanish with $16(5.6 \%)$ respondents. This item also included the possibility to add another foreign language; here, 2 out of 3 respondents mentioned Latin $(0.7 \%)$.

The two closed items of the questionnaire were devised to reveal students' awareness of the possibilities of outgoing international mobility organized by their secondary school and about the possibilities of outgoing international mobility in cooperation with Erasmus+ or other institutions. Respondents could answer: "yes", "no", "don't know". A total of $268(93.1 \%)$ respondents claimed that their secondary school organized outgoing international mobility. A total of $10(3.5 \%)$ students answered that their school did not organize outgoing international mobility, and another 10 (3.5\%) students did not know whether their school organized outgoing international mobility. Although some secondary schools do not offer outgoing international mobility, most students expressed interest in outgoing international mobility in an additional question following a negative answer. A total of 268 respondents answered the question concerning whether their school organized outgoing international mobility in cooperation with Erasmus+ or other institutions, of which $75(28.0 \%)$ students answered yes, $72(26.9 \%)$ answered no, and $121(45.1 \%)$ students did not know about any cooperation with other institutions organizing secondary school students' mobility. Consequently, a question arises as to why the awareness of cooperation with other institutions is so low: Is it because of lack of awareness of students or little interest on the part of students to participate in outgoing international mobility? What is the cause and what is the result of students' low awareness?

In the sample, $114(42.5 \%)$ students took part in one of the offered outgoing international mobilities, while $154(57.5 \%)$ students did not take part in any mobility. In case students had not participated in mobility organized by their school, they were asked about the reasons using an open questionnaire item. The most frequently cited reasons were that students were not interested in the offer, they thought their language skills were insufficient, mobility was too expensive, in secondary schools the preference is given to students in higher classes, or students were not much interested in travelling. Students would be willing to change their opinion if the destinations were more attractive, if they travelled by plane, if the trips took place on a different date, if the whole class participated, or if they were accompanied by a different teacher.

Among the students who participated in outgoing international mobility were 61 (53.5\%) students who participated once, 28 (24.6\%) students who participated twice, and $25(21.9 \%)$ students who participated three or more times. Students were able to specify what kind of mobility they took part in using an open item. The majority of students travelled abroad as part of an excursion abroad; this option was selected by $69(42.3 \%)$ students. A stay abroad was selected by $55(33.7 \%)$ students, exchange stays abroad were selected by $20(12.3 \%)$ students, language courses abroad by $11(6.7 \%)$ students, sports stays abroad by $5(3.1 \%)$ students. Three students wrote down that they made a "visit to a partner school" $(1.8 \%)$. No respondents selected the option of a work stay abroad. A total of $42(36.8 \%)$ students did not know or were not aware of financial support provided by the school for outgoing international mobility, 36 (31.6\%) students said that financial support was not possible, and the remaining 36 (31.6\%) students claimed that their school financially supports students when they travel abroad.

Subsequently, students who had already participated in outgoing international mobility evaluated their expectations before going abroad on a scale of 1 to 5 ( 1 is the lowest and 5 the highest) based on the 5 presented aspects. In the following item, they reflected upon the extent to which their expectations were met. On average, students had the highest expectations regarding the possibility to "get to know a new environment" (4.228, $\mathrm{SD}=1.068)$. On average, students had the lowest expectations regarding the possibility to "acquire new experience in my field of study" $(2.921, \mathrm{SD}=1.458)$. As with the previous item, expectations were best met regarding the possibility to "get to know a new environment" $(4.035, \mathrm{SD}=1.084)$ and, conversely, they were met the least regarding the possibility to "acquire new experience in my field of study" (2.658, SD=1.450). Based on these findings, it can be concluded (see Figure 1) that in general students' expectations were slightly higher than their reflection on how the expectations were met.

For the 114 students who had taken part in outgoing international mobility, discrepancies between expectations (item 13) and fulfilment of expectations (item 14) were determined based on the 
5 presented aspects. The total discrepancy is determined as the sum of differences in individual aspects of expectations and their fulfilment. Descriptive values of total discrepancy in assessment of expectations and fulfilment of expectations are given in Table 1.

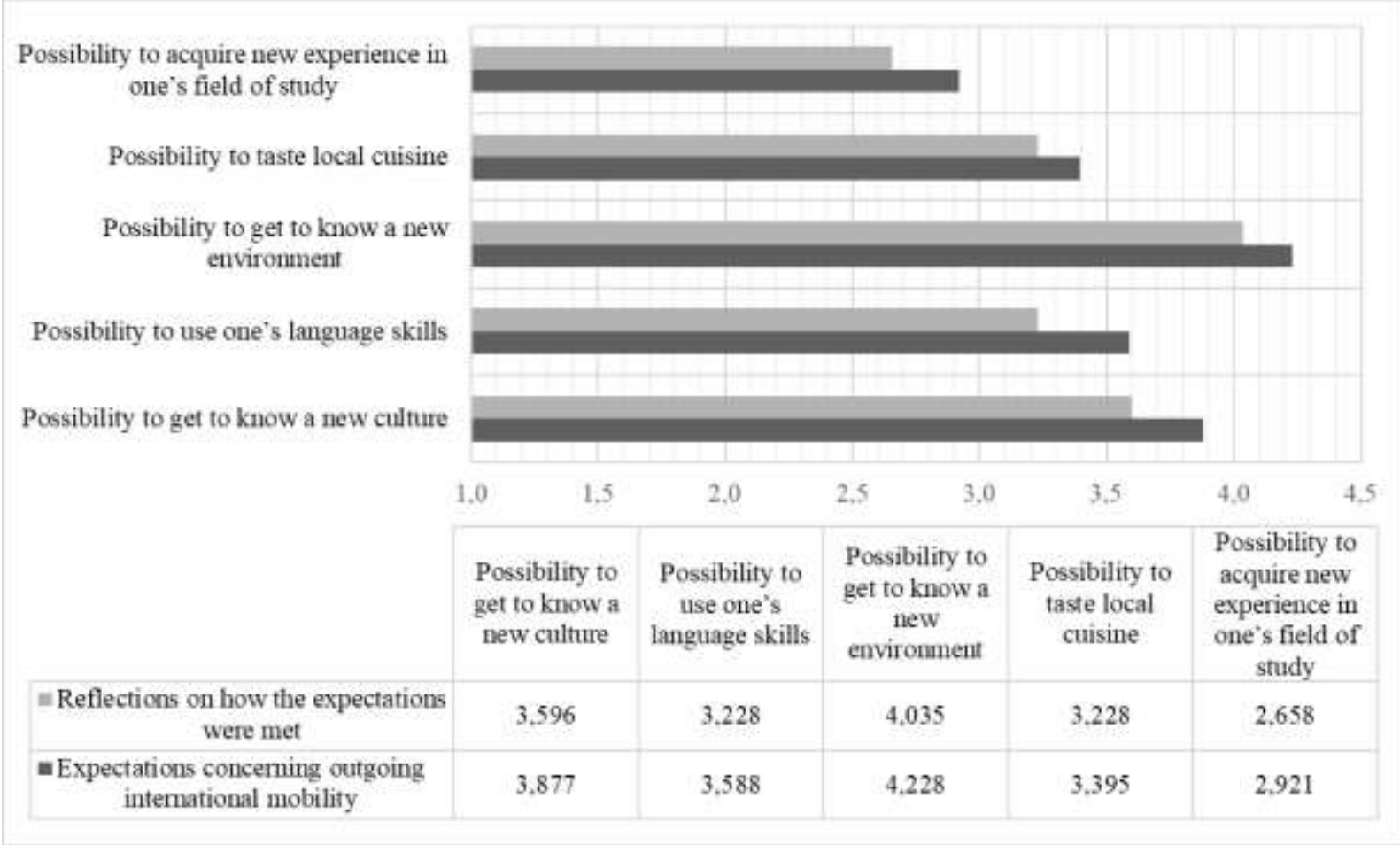

Figure 1. Expectations concerning outgoing international mobility and reflections on how the expectations were met.

Outgoing international mobility exceeded expectations (sum of differences greater than or equal to -1) in $27(23.7 \%$ ) students, met expectations (sum of differences equals 0 ) in 29 (25.4\%) students, and 58 $(50.9 \%)$ students had higher expectations. The sum of differences in expectations and fulfilment of expectations is highest in case of the "possibility to use one's language skills" $(\Sigma=44)$, followed by the possibility to "get to know a new culture" $(\Sigma=37)$, and the possibility to "acquire new experience in one's field of study" $(\Sigma=30)$. A lower sum of differences in expectations and fulfilment of expectations is to be seen in case of the possibility to "taste local cuisine" $(\Sigma=23)$ and the possibility to "get to know a new environment" $(\Sigma=26)$.

Table 1

\section{Total discrepancy in assessment of expectations (item 13) and fulfilment of expectations (item 14) of outgoing international mobility}

\begin{tabular}{|l|l|l|l|c|c|c|}
\hline $\begin{array}{l}\text { Total discrepancy in assessment of expectations and } \\
\text { fulfilment of expectations concerning outgoing } \\
\text { international mobility (on a scale from 1 to 5; 1 is the } \\
\text { lowest and 5 the highest) }\end{array}$ & $\mathbf{Z}$ & & & & & \\
\hline Mobility exceeded expectations & 27 & -2.519 & 2.331 & -68 & -12 & -1 \\
\hline Mobility met expectations & 29 & 0.000 & 0.000 & 0 & 0 & 0 \\
\hline Expectations of mobility were higher & 58 & 3.931 & 3.084 & 228 & 1 & 16 \\
\hline Total & 114 & 1.404 & 3.677 & 160 & -12 & 16 \\
\hline
\end{tabular}

In general, the benefits of outgoing international mobility in the given 5 aspects were confirmed in the selected sample of 114 students in the correlation matrix, see Table 2. Pearson's correlation coefficients confirming the relation between expectations and fulfilment of expectations in the given aspects at significance level of $5 \%$ are shown in Table 2 . The range of coefficients is highest in case of the 
possibility to "acquire new experience in one's field of study" (0.693) and lowest in case of the possibility to "taste local cuisine" (0.523). Significant correlations were also confirmed for the following expectations and fulfilment of expectations:

- between the expectation concerning the possibility to get to know a new culture and the expectations concerning the possibility to get to know a new environment (0.504);

- between the expectation concerning the possibility to get to know a new environment and the fulfilment of expectation concerning the possibility to get to know a new culture (0.420);

- between the fulfilment of expectation concerning the possibility to get to know a new culture and the fulfilment of expectation concerning the possibility to get to know a new environment $(0.463)$;

- between the fulfilment of expectation concerning the possibility to use one's language skills and the fulfilment of expectation concerning the possibility to acquire new experience in one's field of study (0.459);

- between the fulfilment of expectation concerning the possibility to get to know a new environment and the fulfilment of expectation concerning the possibility to taste local cuisine (0.454).

Table 2

Correlation matrix of the selected 5 aspects of expectations and fulfilment of these expectations concerning outgoing international mobility

\begin{tabular}{|l|c|c|c|c|c|c|c|c|c|c|}
\hline & E1 & E2 & $\mathbf{E 3}$ & $\mathbf{E 4}$ & $\mathbf{E 5}$ & $\mathbf{F 1}$ & $\mathbf{F 2}$ & $\mathbf{F 3}$ & $\mathbf{F 4}$ & F5 \\
\hline E1 & 1 & 0.271 & 0.504 & 0.269 & 0.183 & 0.658 & 0.358 & 0.362 & 0.219 & 0.207 \\
\hline E2 & 0.271 & 1 & 0.366 & 0.238 & 0.348 & 0.302 & 0.641 & 0.186 & 0.162 & 0.271 \\
\hline E3 & 0.504 & 0.366 & 1 & 0.271 & 0.181 & 0.420 & 0.274 & 0.569 & 0.129 & 0.169 \\
\hline E4 & 0.269 & 0.238 & 0.271 & 1 & 0.242 & 0.295 & 0.210 & 0.191 & 0.523 & 0.143 \\
\hline E5 & 0.183 & 0.348 & 0.181 & 0.242 & 1 & 0.134 & 0.294 & 0.129 & 0.189 & 0.693 \\
\hline F1 & 0.658 & 0.302 & 0.420 & 0.295 & 0.134 & 1 & 0.422 & 0.463 & 0.374 & 0.262 \\
\hline F2 & 0.358 & 0.641 & 0.274 & 0.210 & 0.294 & 0.422 & 1 & 0.270 & 0.280 & 0.459 \\
\hline F3 & 0.362 & 0.186 & 0.569 & 0.191 & 0.129 & 0.463 & 0.270 & 1 & 0.454 & 0.225 \\
\hline F4 & 0.219 & 0.162 & 0.129 & 0.523 & 0.189 & 0.374 & 0.280 & 0.454 & 1 & 0.321 \\
\hline F5 & 0.207 & 0.271 & 0.169 & 0.143 & 0.693 & 0.262 & 0.459 & 0.225 & 0.321 & 1 \\
\hline
\end{tabular}

\section{Legend:}

E1 - Expectations concerning the possibility to get to know a new culture

E2 - Expectations concerning the possibility to use one's language skills

E3 - Expectations concerning the possibility to get to know a new environment

E4 - Expectations concerning the possibility to taste local cuisine

E5 - Expectations concerning the possibility to acquire new experience in one's field of study

F1 - Fulfilment of expectations concerning the possibility to get to know a new culture

F2 - Fulfilment of expectations concerning the possibility to use one's language skills

F3 - Fulfilment of expectations concerning the possibility to get to know a new environment

F4 - Fulfilment of expectations concerning the possibility to taste local cuisine

F5 - Fulfilment of expectations concerning the possibility to acquire new experience in one's field of study

Out of the total of 114 students who had taken part in outgoing international mobility, 103 (90.4\%) used a foreign language to communicate abroad, only $11(9.6 \%)$ students did not have an opportunity to use a foreign language (for both situational and personal reasons). The 18 th item in the online questionnaire survey evaluated the course of outgoing international mobility in 6 specific aspects on a scale from 1 to 4 (1 - agree, 2 - rather agree, 3 - rather disagree, 4 - disagree) (see Table 3). Students assessed as best the amount of provided information (average $1.456, \mathrm{SD}=0.715$ ). They assessed as worst the benefits for their field of study (average 2.211, $\mathrm{SD}=0.978$ ).

Although students' expectations exceeded the fulfilment of the expectations they had of outgoing international mobility, a total of $110(96.5 \%)$ students would recommend their peers the experience of travelling abroad in the form of international mobility organized by their school, increasing the 
probability to yield many benefits, including language competence, increased awareness of cultural differences and the ability to negotiate meaning across borders, both intelligently and competitively, with rewards for the individual and for society (Fabricius, Mortensen, Haberland, 2017; Spencer-Oatey, Dauber, 2019). Only 4 (3.5\%) students would not recommend the experience of travelling abroad in the form of international mobility organized by their secondary school.

Table 3

Overall assessment of the course of student's mobility (item 18)

\begin{tabular}{|l|c|c|c|}
\hline $\begin{array}{l}\text { How do you assess the course of the mobility? }(1-\text { agree, } 2 \text {-rather } \\
\text { agree, } 3-\text { rather disagree, } 4-\text { disagree })\end{array}$ & N & Average & SD \\
\hline We received sufficient information about the mobility & 114 & 1.456 & 0.715 \\
\hline Transport was comfortable & 114 & 1.956 & 0.777 \\
\hline Breaks and free time were sufficient & 114 & 1.851 & 0.901 \\
\hline Visited places were interesting & 114 & 1.632 & 0.752 \\
\hline Costs of the trip were manageable & 114 & 1.886 & 0.835 \\
\hline Mobility was beneficial for my field of study & 114 & 2.211 & 0.978 \\
\hline
\end{tabular}

The authors are aware of methodological limitations that could affect the validity of results. They include not taking into account the period of time that has elapsed since the last international mobility. Further, in the future, the initial study should be expanded to include formal assessment that the students fill in after the mobility.

\section{Conclusions}

Based on the results of the questionnaire survey, it can be recommended to secondary schools that they should increase their students' awareness of outgoing international mobility. Students can receive information not only from teachers, but also from ad hoc notice boards dedicated to mobility, bookmarks on websites or social media. Students should be informed about all kinds of possibilities of cooperation and obtaining financial support. Providing this information could encourage many students to travel abroad also independently of organized school activities. Another possibility how to inform about mobility and boost interest among students who have not been interested in it so far is to organize socalled international days (or weeks). Photos from international mobility could be exhibited in school and brief informative lectures could be organized, ideally by students for students. In case of outgoing international mobility that is very popular, it is advisable to increase the capacity of the trip or organize the same mobility more often to satisfy demand. Based on students' demand, expanding the portfolio of the countries to which trips are organized could be an option, focusing on smaller groups of students, or offering the possibility of travelling by plane and thus being able to visit more distant countries.

Correlations have confirmed that outgoing international mobility meets students' expectations in the five monitored aspects. Nevertheless, the greatest drawback indicated in the questionnaire survey is the low level of specialization of outgoing international mobility in terms of limited contribution to the given field of study. Therefore, it would be advisable to supplement the offer of outgoing international mobility with possibilities of vocational training abroad, such as visits to foreign companies, expansion of the network of partner schools, as well as adding destinations of specialized internships abroad. Before or after the mobility it is advisable to summarize, discuss, and explain the specialization aspect of the mobility to students. It is important to show them not just the fun side of international mobility, but also the reality of working or educational environment so that students are able to make a connection between knowledge and skills on the one side and practice on the other.

\section{Bibliography}

1. Dvorakova M. (2012). Tradice skolnich vyletu a jejich soucasnost [Tradition of School Trips and their Present Concept]. Jihlava: Vysoka skola Polytechnicka Jihlava. Retrieved from https://is.vspj.cz/bp/get-bp/student/25918/thema/1376 (in Czech)

2. eTwinning is the Community for Schools in Europe. (2019). eTwinning. Retrieved from https://www.etwinning.net/en/pub/index.htm 
3. European Commission. (2019). eTwinning: the community for schools in Europe. Retrieved from https://ec.europa.eu/programmes/erasmus-plus/sites/erasmusplus/files/factsheetetwinning_en.pdf

4. Fabricius A.H., Mortensen J., Haberland H. (2017). The Lure of Internationalization: Paradoxical Discourses of Transnational Student Mobility, Linguistic Diversity and Cross-Cultural Exchange. Higher Education: The International Journal of Higher Education Research, 73(4), 577-595. doi: 10.1007/s10734-015-9978-3

5. Mizikaci F., Arslan Z.U. (2019). A European Perspective in Academic Mobility: A Case of ERASMUS Program. Journal of International Students, 9(2), 705-726. Retrieved from https://www.ojed.org/index.php/jis/article/view/1138

6. Petzhold K., Bucher H. (2018). The Academic Mobility Regime: Analysing Perceptions of Students and Academic Staff. International Review of Social Research, 8(1), 98-108. doi: 10.2478/irsr-2018-0011

7. Raitskaya L., Tikhonova E. (2019). A University Course of Intercultural Communication: Fostering Students' Skills and Competence. In V. Dislere (Ed.), The Proceedings of the International Scientific Conference Rural Environment. Education. Personality (REEP), 12. Jelgava: Latvia University of Life Sciences and Technologies, 152-157. doi: 10.22616/REEP.2019.019

8. Roskosa A., Stukalina Y. (2018). Management of a Study Programme in the Context of Quality Assurance in Higher Education. In V. Dislere (Ed.), The Proceedings of the International Scientific Conference Rural Environment. Education. Personality (REEP), 11. Jelgava: Latvia University of Life Sciences and Technologies, 118-127. doi: 10.22616/REEP.2018.014

9. Roskosa A., Stukalina Y. (2019). Marketing in Higher Education in the Agenda of Increasing International Enrolment. In V. Dislere (Ed.), The Proceedings of the International Scientific Conference Rural Environment. Education. Personality (REEP), 12. Jelgava: Latvia University of Life Sciences and Technologies, 119-125. doi: 10.22616/REEP.2019.015

10. Smékalová L., Němejc K. (2016). Transferable Competencies of Graduates of Vocational Education: a Retrospective Survey 2007-2014. In V. Dislere (Ed.), The Proceedings of the International Scientific Conference Rural Environment. Education. Personality (REEP), 9. Jelgava: LLU, 106-113. Retrieved from https://llufb.llu.lv/conference/REEP/2016/Latvia-UnivAgricult-REEP-2016proceed2255-808X-106-113.pdf

11. Spencer-Oatey H., Dauber D. (2019). Internationalisation and Student Diversity: How Far are the Opportunity Benefits Being Perceived and Exploited? Higher Education, 78(6), 1035-1058. doi: 10.1007/s10734-019-00386-4

12. Welcome to Youthpass. Recognition Tool for Non-Formal \& Informal Learning in Youth Projects. (2019). Youthpass. Retrieved from https://www.youthpass.eu/en/

13. Zhanguzhinova M., Magauova A., Salkhanova Z., Urazbayeva G. (2018). Review of the International Experience upon Professional Preparation of Teachers. In V. Dislere (Ed.), The Proceedings of the International Scientific Conference Rural Environment. Education. Personality (REEP), 11. Jelgava: Latvia University of Life Sciences and Technologies, 155-161. doi: 10.22616/REEP.2018.018 